Article

\title{
Regenerativescapes: Incremental Evaluation for the Regeneration of Unresolved Territories in East Naples
}

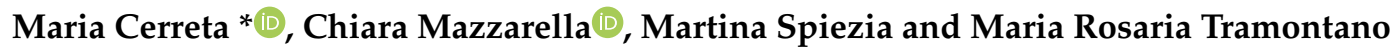 \\ Department of Architecture, University of Naples Federico II, 80134 Naples, Italy; \\ chiara.mazzarella@unina.it (C.M.); mart.spiezia@studenti.unina.it (M.S.); \\ mariar.tramontano@studenti.unina.it (M.R.T.) \\ * Correspondence: maria.cerreta@unina.it
}

Received: 27 July 2020; Accepted: 24 August 2020; Published: 27 August 2020

\begin{abstract}
The unresolved territories are privileged places for the proliferation of degradation phenomena that affect the environment and human well-being. The impacts of their critical conditions go beyond the limits of the damaged urban fragments, involving the built environment, society, economy, culture, and conditioning quality of life. This paper proposes a methodological approach to landscape design supported by an evaluation framework to orient strategic design planning with specific attention to unresolved territories consistent with the circular economy perspective. The circular city principles are applied to landscape spatial planning, by operationalising Ecosystem Services, Landscape Services, and Ecosystem Disservices, as interpretative categories for multi-dimensional regenerative strategies. Starting from a theoretical framework, the objective of the analysis is to implement an approach to the regenerative design of landscapes of waste, defined wastescapes. The industrial area of East Naples is the case study where an incremental evaluative approach has been defined to design scenarios to provide services and values, aimed to drive the conversion in a regenerativescape. A multi-criteria analysis through preference ranking organisation method for enriched evaluation (PROMETHEE)-GAIA method has been implemented to compare the base case scenario with two incremental new scenarios and identify situated sustainable priorities.
\end{abstract}

Keywords: circular city; wastescapes; regenerative design; landscape services (LS); ecosystem services (ES); ecosystem disservices (EDS); fundamental human needs (FHN); multi-dimensional evaluation; decision-making process; MCDA; PROMETHEE-GAIA method

\section{Introduction}

Two-thirds of the European Union (EU) population resides in urban areas, and they use around $80 \%$ of energy resources [1], determining critical conditions for quality of life and increasing crisis complex environments. The widespread crisis in urban areas in recent decades has led to the definition of European plans and agendas to adopt common policies [2] and to activate shared processes to support cities policies, where human settlements act as main catalysts for creativity and innovation across the EU. Anyhow, they are also places where various persistent environmental problems reach the most worrying levels, especially related to waste proliferation. Indeed, almost $70 \%$ of waste generated globally is currently not reused or recycled [3], and cities contain both the cause and solution of most of today's global challenges. These conditions need serious policies and programs, planned and managed with a multidisciplinary approach, where urbanisation can drive the change, turning problems into opportunities [4].

The New Urban Agenda, adopted at the United Nations Conference on Housing and Sustainable Urban Development (Habitat III), aids as a shared vision for world urban areas for the next 20 years [5]. 
It is a guide for building prosperous cities and centres of cultural and social well-being while protecting the environment. The Agenda also specifies guidance for achieving the Sustainable Development Goals and provides the underpinning for actions to address climate change. Priorities like air quality, housing, the inclusion of migrants and refugees, urban poverty, jobs and skills, circular economy, digital transition, urban mobility, climate adaptation, energy transition, public procurement, and sustainable land use partly concur in the Sustainable Developments Goals (SDG) 11, "Make cities inclusive, safe, resilient and sustainable": sustainable cities and communities due to the complex configuration of the dynamics influence urban challenges.

In the above perspective, a multi-dimensional approach is required to analyse and operationalise scenarios able to trigger action strategies for regenerative processes and to reduce or eliminate degradation conditions, with specific attention to unresolved territories and expression of different kinds of crisis. Degradation is a product of waste, a phenomenon to be considered not only materially, but also as an immaterial effect of choices on those neglected parts of the built environment.

From this position, extending the view on the waste phenomenon in urban space, and looking at the landscape of waste, the concept of wastescape [6] has been explored in the Horizon2020 REPAiR project, Resource Management in Peri-Urban Areas. Going beyond Urban Metabolism [7]. The project aimed to explore methodologies and tools to integrate the management of urban metabolism waste resources with the strategic management of the peri-urban territories [8], starting from the circular economy (CE) paradigm $[9,10]$, and to elaborate eco-innovative solutions and strategies [11] for resources management and wastescape regeneration.

The study started from a mapping of metabolic flows, together with the identification of the wastescape. From the literature on American drosscapes [12], those parts of the unsolved territories that have been excluded from urban growth processes or abandoned as a result of new economic dynamics were classified. Three interconnected fields of analysis concur to the rise of spatial phenomena of waste: spatial, material flow, and socio-economic phenomena. Wastescapes have been defined as places in crisis according to their main spatial categories identified in peri-urban areas: Degraded lands; degraded water and connected areas; declining fields, settlements, and buildings in crisis; "dross" of facilities and infrastructure, the operational infrastructure of waste [13].

The main character of cities and contemporary culture is represented by the fragment, such a chaotic dispersion of things, subjects, practices, and economies [14]. In this context, wastescapes are critical fragments of contemporary growth, excluded or disconnected from the rest of the urbanised areas, witnesses of the failure of economic processes for multiple causes. They can cause negative impacts, risks, and/or disamenities. Wastescapes are places of ongoing degenerative processes due to abandonment, pollution, and isolation that lead to ecosystem depletion, social risks, economic devaluation, and other environmental risks for human beings, flora, and fauna. Although waste was mostly considered as a problem to solve for decades, nowadays it is recognised as a new economic resource to be used [15] in the CE paradigm for the built environment [16].

In the REPAiR project, waste and wastescapes have been considered key elements to close the loop. Circular supply chains are the core of new urban scenarios in circular cities, to implement looping actions [17]. Unsolved territories contain significant regenerative potential. Wastescapes adaptability is precisely in the emergency scenarios they configure because these fringe areas [18] are suitable for new shifting scenarios. Modifying a perfectly functional system requires multiple evaluations, and a strong reason to start a change.

From this point of view, multi-dimensional urban challenges can turn the tide elaborating alternatives starting from the most critical urban landscapes. This paper copes with the issue of a class of unsolved territories in the framework of wastescapes, considering strategies to subvert the degenerative effects of abandonment places in urban and peri-urban areas into values and services for human well-being and the environment. The regeneration strategies proposed in the case study have been developed based on a methodology that starts with the identification of the Ecosystem and Landscape Services, defining an incremental evaluation process, oriented to regenerate wastescapes 
and, at the same time, to make landscapes able to activate new regeneration processes according to a continuous loop, in a process consistent with the principles of CE, called "regenerativescapes". The following paragraphs introduce the theoretical background, to define an approach to answer the question: How to convert a wastescape into a regenerativescape? Section 2 analyses the role of Urban Ecosystem Services and Disservices for wastescape regeneration, and explains the concept of regenerativescape. Section 3 articulates the description of the methodological framework (Section 3.1), the case study (Section 3.2), the incremental evaluation framework, with identification of criteria and indicators for the assessment of a regenerative urban scenario (Section 3.3), and project scenarios defined as an evolutive transformation process (Section 3.4). Section 4 describes the results and Section 5 presents a discussion of the results and outlines possible conclusions, opening to the next steps of the ongoing research.

\section{Regenerativescape: A Circular Approach for Wastescapes Regeneration}

A wastescape is a part of the landscape that does not provide any kind of service, both natural and man-made. The condition of environmental degradation in urban settlements requires first the provision of ecological services. Through strategic planning, natural ecosystems in urbanised areas can generate value chains and socio-economic development opportunities. Environmental quality is the first and essential requirement in a liveable city. Urban ecosystem services (UES) play a key role in this challenge [19]. They may not only be ecologically and socially beneficial but also economically advantageous [20], to be appreciated in urban planning. Urban planning and policy are responsible for the equitable distribution of UES [21].

Ecosystem health [22] and human well-being are a unicum, in particular in urban areas. A concept of fundamental importance affirmed and developed in the Millenium Ecosystem Assessment (MEA) is the link between the ecosystem services (ES) and the well-being of society. The basic concept is that in general, our well-being depends on the services provided by nature. According to the MEA, biodiversity in urban areas mainly performs air, water, and climate regulation services, becomes cultural heritage and supports cultural services. In peri-urban transition areas close to urban centres, cultivated areas provide provisioning, regulation, and cultural services. These services that nature offers when it is respected and cared for by human beings contribute to well-being by producing not only environmental but also economical and socio-cultural values. For instance, nature-based activities can be related to management and production in the agri-food chain, and the tourist and leisure activities for the inhabitants of the city [23]. More generally, UES respond to many different human needs.

The fundamental human needs (FHN) have been outlined in Max-Neef's matrix of needs and satisfiers [24]. They are needs of subsistence, protection, affection, understanding, participation, leisure, creation, identity and freedom, and they are expressed in being (qualities), having (things), doing (actions), and interacting (setting). Needs and satisfiers vary through time and cultures, but fundamentals are constant in human-scale development approach [25]. Human needs and subjective environmental well-being find common ground in the FHN and ES integrated approach [26]. Habitat change, climate change and pollution are the leading direct drivers of change in biodiversity and ecosystems [23].

ES are a comprehensive approach to landscape analysis, identifying functions and services to address regeneration $[25,26]$. Even though the number of studies concerning ES valuation has been growing, the practical application of evaluation has been criticised and its utility for policy guidance uncertain [27]. According to some authors, beyond an idealised vision of the natural environment, in urbanised areas, it is also essential to take into account the Ecosystem Disservices (EDS) produced from natural elements [28]. EDS are those negative impacts generated by nature to people. Von Döhren and Haase's review on EDS literature with a focus on cities found that most of them are have been studied at a local scale [29]. Significant indicators of EDS are about bio-physical, then economic and, last, cultural-social. Some of the urban EDS identified are: The allergenic potential of respective plants, extensively in areas of non-illuminated parks, a disservice to urban people, but fundamental for some 
nocturnal species; emissions of volatile organic compounds, emissions from maintenance activities, concentrations of particulate matter in the air, an abundance of undesired species, maintenance cost for urban green areas, percentage of tree species susceptible to damage, percentage of trees yielding fruits, number of aged trees, amount of affected infrastructure, number and size of trees near buildings, amount of water used for plant growth, etc. [29]. Lyttymaki affirms that an essential issue of the concept of EDS is not about disparage nature in urban areas, but about putting both ES and EDS under a common evaluation framework [30,31]. Villa, however, argues that the use of the concept of EDS hinders, rather than helps, the development of an integrative and constructive dialogue on conservation and the complex interrelationships between human beings and nature [32]. Equal consideration of services and disservices allows a holistic valuation that captures both positive and negative effects [33], ever-present and object of multiple evaluations.

The definition and the scope of EDS is an open debate. Shackleton et al. [34] in a review of literature about this definition say that disservices are EDS only if they are generated by the Ecosystem rather than human action. For instance, the dropping of litter has been used as an example of an EDS by Lyytimaki and Sipila [35]. Still, the same might be said about aesthetically unpleasing man-made design on the landscape. According to Shackleton et al. [34], human behaviours and values are not ecosystem functions and processes. Although we accept that humans are an integral component of ecosystems, humans themselves and their actions do not constitute ecosystems. In this open debate, the authors do not have a unique position considering ES and EDS of a wastescape. However, before further researches oriented to wastescape evaluation and regeneration, this study considers that both ES and EDS are generated by natural phenomena, put in the same framework to assess a planning strategy for the regeneration of a wastescape.

If we consider cities as living systems, and landscape as a cultural product, wastescapes can be defined as pathologies of urban systems, that need specific but holistic strategies to be healed. The benefit of ES and the impacts of EDS (meant as natural negative effects on human-beings) are components to evaluate for wastescapes regeneration. They can be pursued in an eco-complex approach to the landscape design. Multi-dimensional elements coexist in ecoscape [36]: Geographical landscape, living organisms, economic metabolism, social organisation, and cultural heritage, made of water, fire, soil, wood, living organism, minerals, and human beings.

In a landscape in crisis, UES and ES provide support to repair environmental dysfunctions and to activate services functions, that a site, a neighbourhood, or a city is lacking in [36].

Over time, the study on ES has been accused of anthropocentrism, but man is a living being in nature like other species and like other species uses the resources available for his survival. ES make explicit the dependency relationships between human beings and the natural environment, and in this way, they help protect, manage, and design the natural environment [37].

From this point of view, to investigate and evaluate regenerative development, ecosystem services (ES) and the landscape services (LS) head landscape analysis towards regeneration.

Regenerative design for the built environment has been a widely investigated field in the last decades. From Lyle's first introduction of the concept of "design for regeneration" [38], through the radical ecologist movements, humans are seen as an integral part of nature and partners in the processes of co-creation and co-evolution instead of being mere users of various ES [39]. Integrating FHN, ES, and landscape functions, "capacity of an ecosystem to provide goods and services that satisfy human needs, directly or indirectly", in planning $[40,41]$ is a support to the decision-making for environmental regeneration.

The scenarios caused by climate emergency are indicators of the fact that today it is no longer enough to talk about sustainability. Projects on the natural and built environment cannot exclusively have zero impact but should provide goods and services not only for human beings but for the environment too [42]. While current sustainability practices focus on providing no effects, the restorative design aims to re-establish ecosystems, and regenerative design aims at allowing human and natural 
ecosystems to develop. Regenerative Design [43] is a forerunner concept of the CE. Nowadays, CE has positive effects on job creation and a green transition, strengthening social inclusion.

Environmental regeneration leads to an improvement in the living conditions of human and non-human beings. It is not possible to restore an ecosystem, but regenerating it is possible because it is a living system and not a static entity. In this framework, landscapes of waste need regenerative strategies to provide UES and low energy systems $[44,45]$. The goal in the design of regenerative landscapes, regenerativescape, is to improve the status quo of landscapes of waste, wastescapes, by restoring damaged services and enhancing them with new compatible ones (Figure 1). As well as the natural landscape, a built environment can also go beyond the green building concept and practices [46].

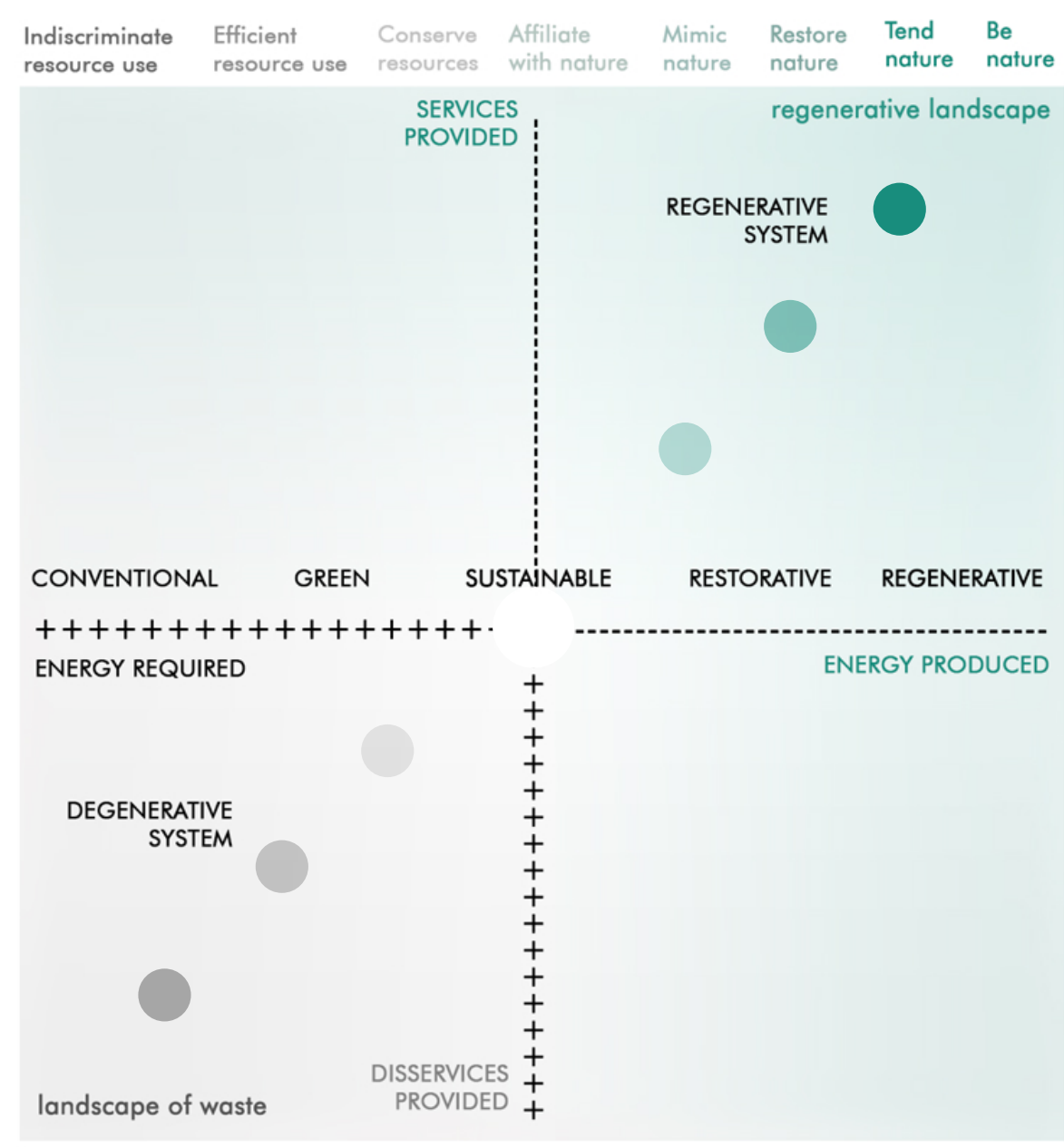

Figure 1. Landscape of waste (wastescapes) and regenerative landscape (regerenerativescape) in the framework of regenerative development. Adaptation on the frame of Mang et Reed, 2016 [42].

In the legacy of deep ecology perspective [47,48], the Regenerative Development investigates how humans can be partners in evolution with nature, going beyond the simple respect of nature. In the Regenerative Development manifesto, Regenesis Group states that the world is complex, and nature does not need our protection, but our collaboration [49]. Because the best response is a local response, there are no standard strategies to copy, but principles to adopt. In this approach, everyone has a crucial role because of the core importance of community engagement in this new symbiotic approach to the environment: A systemic development approach for human well-being [25].

From this perspective, wastescapes are required to be designed not only to limit impacts, but to subvert the scenario by producing positive goods and services. The criteria that a Regenerative Design approach can provide to each wastescape are different and due to site-specific characteristics. It is 
essential to recognise that the question has multiple levels. The first level is a design question about how activities can be designed to harmonise with and support local natural systems. Another level has to do with a community's awareness and the members of the community can be awakened to that connection. To this purpose, some of the practices related to the CE paradigm move in the direction of the principles and objectives defined in the context of Regenerative Design. CE is an expression of a systemic approach to economic development designed to benefit businesses, society, and the environment.

In contrast to the 'take-make-waste' linear model, a CE is regenerative by design and aims to decouple growth from the consumption of finite resources gradually. CE is a restorative and regenerative economy by design, where economic activity builds and rebuilds overall system health, recognising the importance of the economy needing to work effectively at all scales (for big and small businesses, for organisations and individuals, globally and locally) and considering three principles: Design out waste and pollution; keep products and materials in use; and regenerate natural systems [50-52]. The main goal of CE seems to be closing of the supply chains of the production processes in loop. Indeed, in the CE paradigm, waste can be considered a new resource for the built environment [16]. Although the dominance of waste management issues, $\mathrm{CE}$ is not only about waste reuse or recycle.

The dominant economic models are based on a linear system of production, use, and disposal of goods. The linear extraction model leads on the one hand to the depletion of natural resources through extractive activities, with consequent environmental and social impacts, and on the other to the generation of large waste areas for waste management, with vast portions of territory destined for landfills or waste management and treatment plants. RESOLVE framework [52] stands for regenerate (shift to renewables resource, restore ecosystems), share (share assets, prolong life cycle through maintenance and design for durability), optimise (increase performance/efficiency of the product, remove waste in production and supply chain), loop (remanufactured products or components), virtualise (dematerialise goods), and exchange (apply new technologies and choose services instead of a product). Closing the circles of the production systems [53] through industrial ecology processes can lead to integrated and clean production cycles, as well as employment and socio-economic well-being (Figure 2), as it replaces the areas of raw material extraction and material storage areas with new areas of production for all hinges to close circular processes. Human beings are the only terrestrial species that take from the soil large quantities of nutrients necessary for biological processes and rarely return them in a usable form [54].

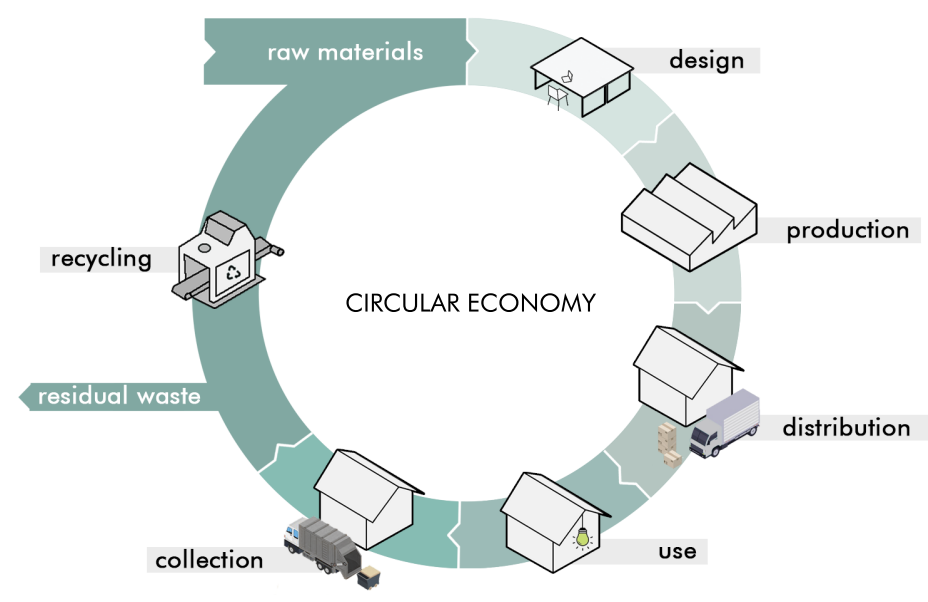

Figure 2. Circular process of material flows.

Even in small urban activities, combining a productive activity with one useful for the recovery or recycling of other waste can generate synergies and complex values with a positive environmental impact, as in the case of the production of compost in combination with the urban agriculture [55]. 
Integrating waste stream management and wastescapes, the designing of circular urban metabolism is once again able to provide material and immaterial benefits for the well-being of human beings and the environment in which they operate.

The current generation shows the limited ability to use primary resources efficiently by still considering goods as disposable products, which, after use, become directly waste. Regenerative Supply Networks [56] can be introduced as a connective element between the analyses of urban metabolism and the territorial dimension of Regenerative Design [57-59].

The methodology adopted to deal with this approach has been the work on a set of criteria useful for the assessment of landscape, taking into account ES and EDS to drive a set of strategies for the urban regeneration of a wastescape in Naples, in the South of Italy. The implementation and optimisation of some composite indicators aim at driving the transition of wastescapes in regenerativescapes, in a progressive and systemic logic to host adaptive processes developed in incremental phases. A final multi-criteria evaluation of the three identified scenarios is presented as a decision support tool of the different design stages.

\section{Materials and Methods}

\subsection{The Methodological Framework}

This research aims to structure an integrated design methodology to the evaluation process for landscape regeneration, with particular attention to the environmental issue. Therefore, an incremental evaluation model has been built, where the different project actions are inserted in progressive and adaptive strategic scenarios supported by a value-based approach to the definition of each phase.

The research explores different approaches to Landscape Services, to define a valid methodology both for men (with whom ecosystem services traditionally compare) and for the environment itself. The definition of ad hoc indicators becomes a tool for knowledge and evaluation of landscape systems. They can simplify complex issues and make them understandable and usable even by non-experts, within the decision-making processes of planning and landscape management.

The study of environmental indicators and their graphic representation is one of the most effective tools for providing a concise description of the state of a given environment and its evolution and ensuring maximum accessibility, comprehensibility, and usability of the information. However, although this theory is widely addressed and analysed in the scientific literature, through the treatment of ES, nothing at a regulatory level makes the practice operational [60]. The indicators of ES and EDS were mainly studied.

The proposed methodology is set out in three main phases (Figure 3):

1. Knowledge process;

2. Design process;

3. Evaluation process.

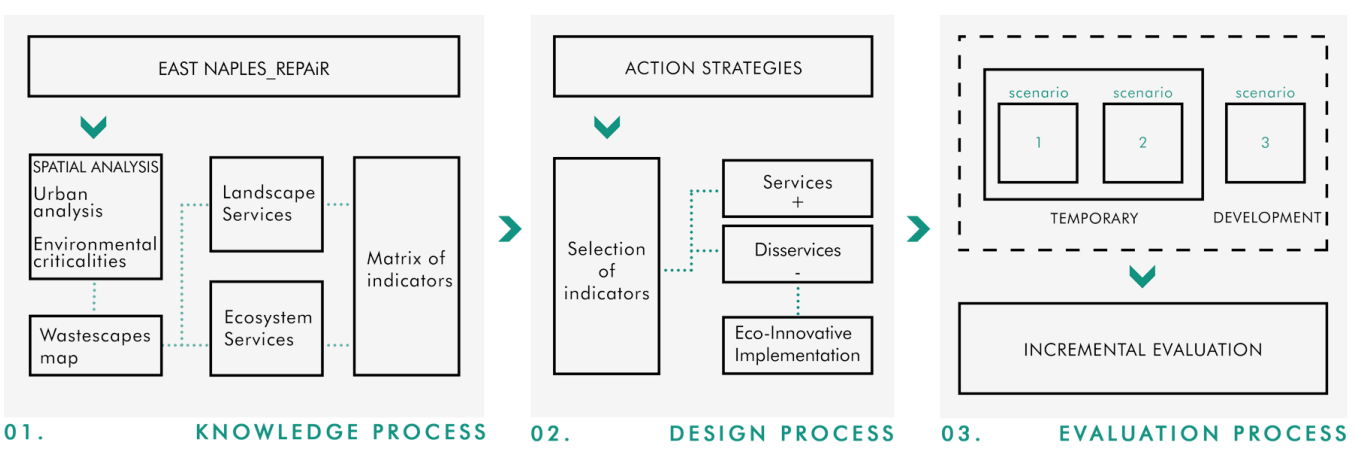

Figure 3. The methodological framework: Steps and contents. 
The knowledge process represents the first phase of the methodology. This phase starts with the identification of the East Naples area, in the South of Italy, as a case study within the European Horizon 2020 project REPAiR. Urbanistic analyses, including qualitative and spatial elaborations, are carried out on the study area, the overlapping of which allows identifying the emergencies and potentials offered by the territory. These features are expressions of different values and are declined in terms of landscape services (LS) and ecosystem services (ES), on which the indicators matrix is built. The second phase consists of the process of developing project scenarios. In this phase, the strategic planning actions are defined and assessed according to the indicators of the relevant services and disservices that the study area returns, as positive and negative impacts.

Finally, the third phase coincides with the evaluation process, in which the three scenarios (the first two attributable to a temporary project and the third to a final project) proposed concerning the predominant actions are analysed, which are assessed in the function of the selected indicators. The evaluation is carried out using the preference ranking organisation method for enriched evaluation (PROMETHEE) method [61-65], which represents a suitable tool for controlling the impacts that a scenario produces by increasing every individual action each time.

\subsection{The Case Study}

The case under examination is that of the four districts of Naples East: Ponticelli, Barra, San Giovanni a Teduccio (Municipality 6), and the Industrial Zone. This context is the flat area on the edge of the consolidated city, identifiable with the plain of the ancient marshes. In the evolution of the city, the configuration of the area has favoured the location of the first railway lines and the first industrial factories, leading it to its destiny as an industrial area and residential worker expansion [66] (Figure 4).
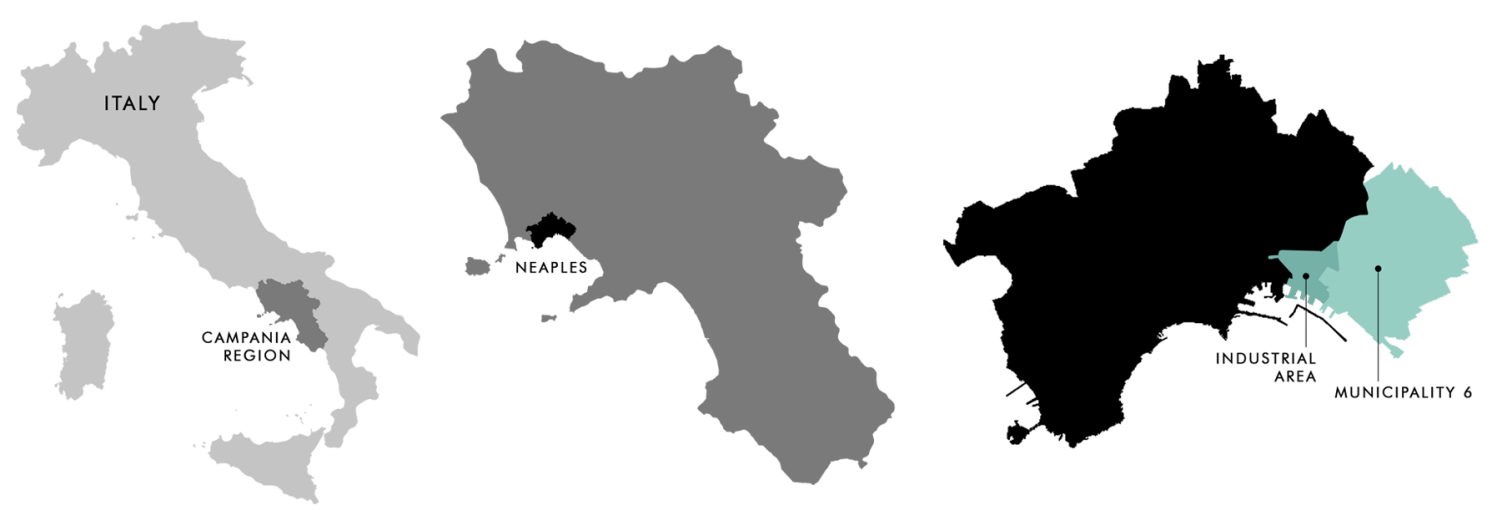

Figure 4. The sample area: Municipality 6 and the industrial area of East Naples.

Today, the eastern area of Naples, with the overlapping of its multiple landscapes, occupies a large portion of the municipal area. This multiplicity constitutes a complex functional mix, the result of a city that is made up of parts linked to chance, dictated by different logics that contaminate, repel each other, fray along the edges; a city that grows involuntarily and uncontrollably.

From the industrial area of the city, the eastern region today presents itself as a cemetery of abandoned structures and boundless spaces left to abandonment and degradation, but at the same time large incubators of potential. It defines that typical assembled urban landscape where industrial and residential areas alternate, abandoned areas and agricultural areas with greenhouses, deposits, landfills (Figure 5).

The case study is used as a basis for analysing the multidisciplinary and complexity that the design took on. If the planning approved in 2008 (preliminary of the Urban Planning Plan for area 13) was based on sustainability criteria, therefore reduction of pollutants, use of renewable energies, and promotion of clean industry, but still with a view to linear economy, today, after about 10 years, 
we are witnessing progress in the approach towards CE logics that aims at no waste and industrial symbiosis, as well as towards the regeneration of the landscape.
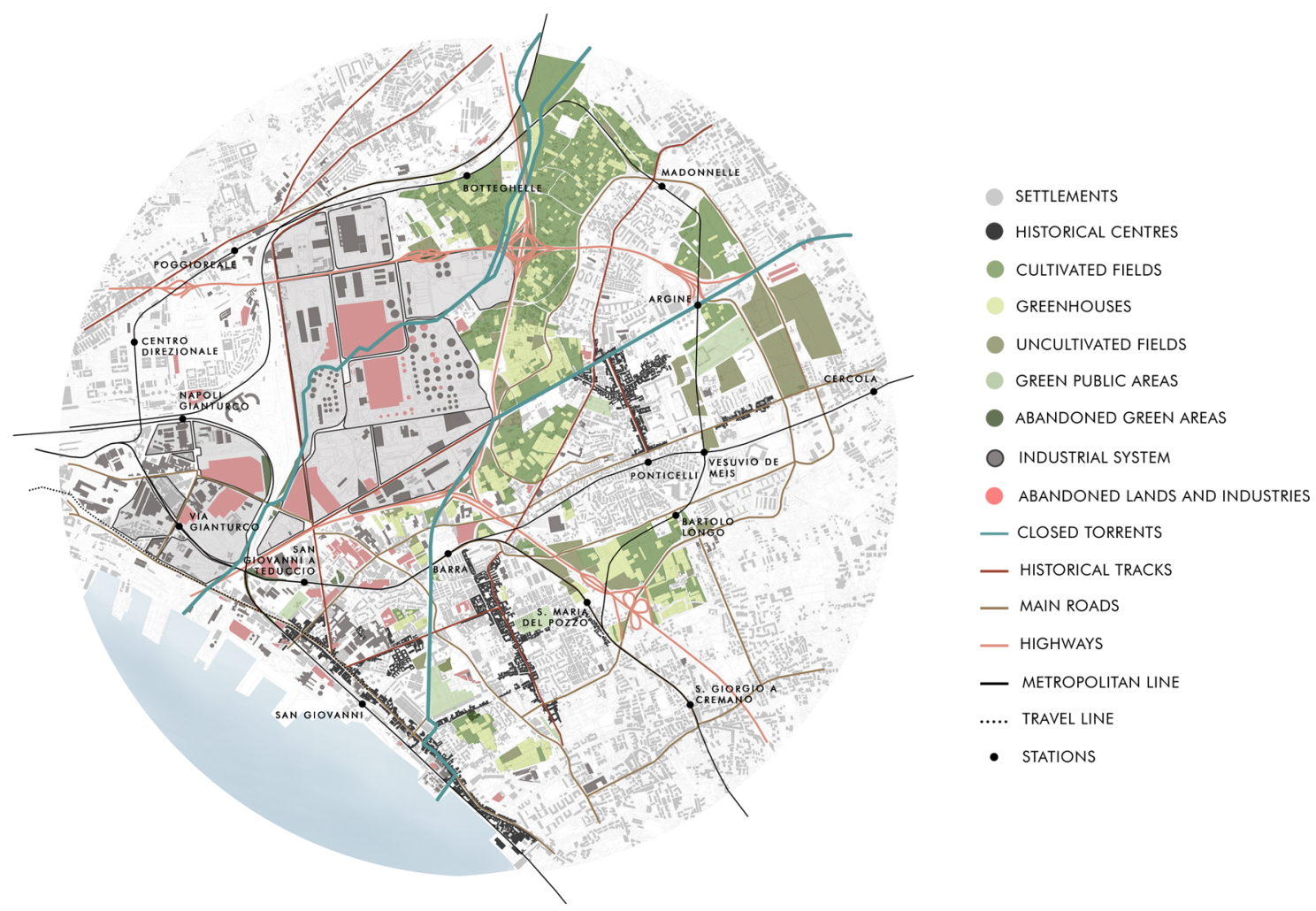

Figure 5. Spatial analysis: Investigation of settlement, environmental, industrial, and infrastructural systems (authors' elaboration).

\subsection{Evaluation Framework: Criteria and Indicators of a Regenerative Urban Scenario}

Indicators, as tools for knowledge and evaluation of landscape systems, transform complex issues into data, making them understandable and usable even by non-experts. The definition of Regenerative Landscape considers three reference criteria:

1. Social regeneration, recognised by the community as a meeting place, support space for life and leisure, as well as a place of culture;

2. Environmental regeneration, defined by the ecosystem complexity; that is, by the complexity of the structure of an environment, measured as a diversity of habitats, productivity, species richness, of the biomass contained in the different trophic levels, and of the energy flows from which they are connected;

3. Economic regeneration, which defines the actions to intervene within a compact and complex context of the production areas.

The indicators selected for each cluster are oriented towards the specific case study knowledge and design. They represent an accurate summary of the reference literature to better respond to planning needs. Given the complexity of the case that includes different ecosystems within it, the table of indicators defines combined matrices where landscape, artificial, and waste ecosystems relate to each other. The ecosystem services were analysed taking into account the treatment of De Groot [67], which focuses mainly on environmental aspects (production of oxygen, biomass, air quality regulation, carbon sequestration and storage, and others). An essential element of the case of Naples, however, is the relationship that ecosystems establish with human beings, with which new services are generated that De Groot does not take into account. For this reason, LS have integrated, which mainly analyses 
services related to social aspects (such as quality of place to work, mental and physical health, landscape enjoyment, and others).

It is also necessary to take into account those services which, however, bring negative aspects, that is, disservices, to human beings. These have been described as EDS and can relate to the economic aspect (such as costs due to the increase in maintenance of the green or to damage to structures and people), the social aspect (such as the discomfort produced by allergy to pollen or the presence of animals as carriers of diseases), and the environmental aspect (for example the discomfort caused by dark or poorly maintained green spaces or by the presence of animals inside public spaces), extended and in some cases re-adapted to meet the needs of the specific case better.

The indicators identified are grouped according to the social, environmental, and economic regeneration criteria to be pursued and, in turn, in the four classes of production, regulation, information, and habitat functions. This research summarises indicators related to Ecosystem and Landscape Services and Ecosystem Disservices, as shown in Figure 6.

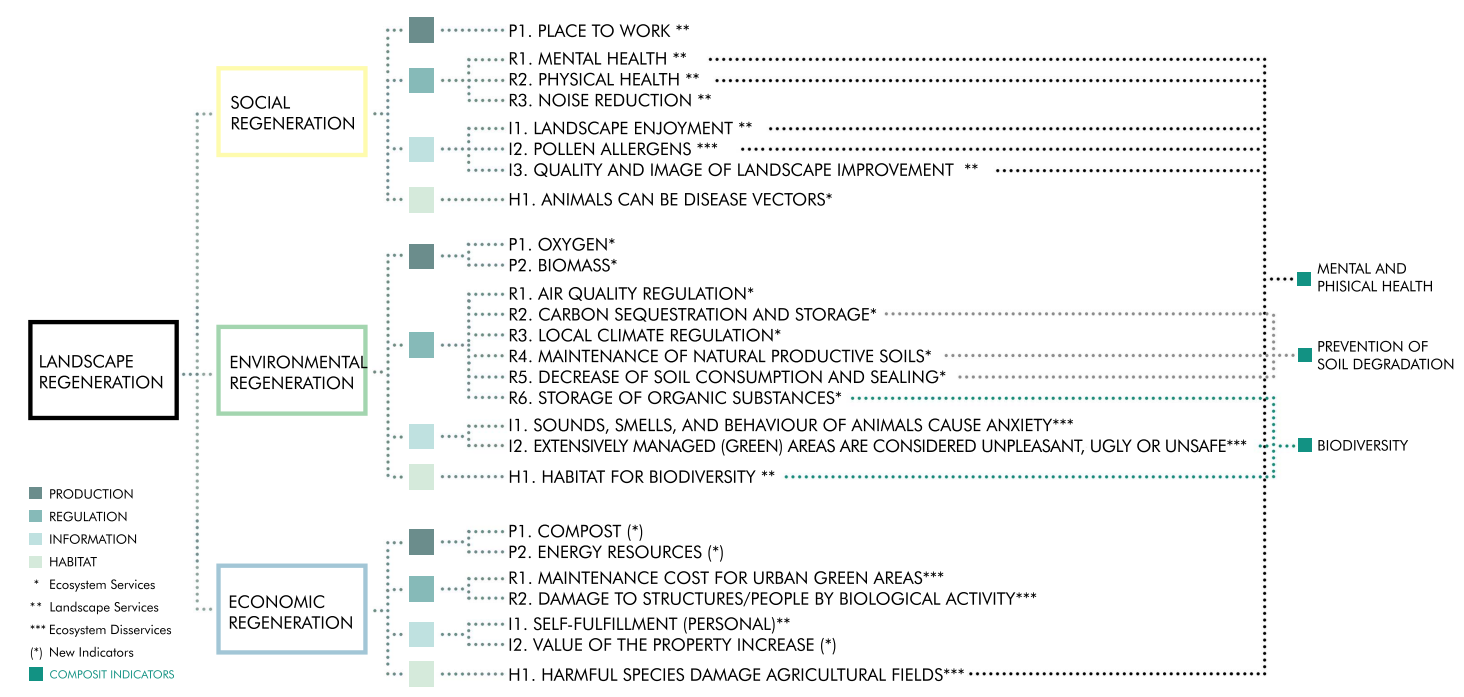

Figure 6. Indicators selection for the Ecosystem and Landscape Services and Ecosystem Disservices (authors' elaboration).

This cognitive reference framework has been taken as the basis of knowledge to define the criteria for the design of regenerative landscape scenarios.

\subsection{Incremental Transformation Process: Project Scenarios}

Starting from the identification of relevant elements, and from the recognition of positive results, an incremental transformation process has been carried out. The paradox of planning for cities in evolution [68] has been combatted by activating, in successive stages, the circular metabolism of the selected area starting from its regenerative components. The goal is to trigger multiple cycles of increasing intensity to create a new sustainable urban ecosystem over the long term. The transformation takes place through incremental and adaptive phases necessary to produce partial results that become the generative basis of the next phase. The proposed process is that of Cityforming, a design device intended by UniPa's Creative City Lab, which is made operational in the case study, as a tool for reactivating urban metabolism and achieving the general objective of the project [69].

The analysed industrial area is currently occupied by oil and gas deposits, namely 97.6 hectares of Kuwait Petroleum Italy to 12.6 hectares by Eni Agip; abandoned industrial settlements, that were former refineries; crumbling structures.

The design proposal takes place in a phase previous to the final disposal of the area, or in the phase of the creation of the fertile substrate where the new Ecosystem will develop. The goal is to 
contribute to the long-term process by generating new metabolisms. The design actions for the three incremental phases have, therefore, been defined.

The first two phases, which can be implemented in the short and medium-term, coincide with the transition scenario, which precedes the divestment. This scenario constitutes the driver that invests the power to transform a wastescape into a regenerativescape: A landscape that, by enabling social and ecological systems, acts as a dispenser and catalyst for a positive change within the place where it is located [70]. They provide for the environmental regeneration of areas that have already been abandoned for some time through integrated remediation systems perfected with bioremediation techniques. The area is reclaimed and acquires a new identity of a peri-urban park and forest of ecosystem recharge. This action contributes to the improvement of UES, like the air quality and pollution mitigation [71] and LS, as aesthetics of the place and spiritual benefit to inhabitants of the district [72]. It prepares the next step that provides for the economic and identity activation of the area with the enhancement of social, cultural and economic functions within the peri-urban forest.

The third phase involves the implementation of the final project in a long time. This scenario is one in which the highest number of variables come into play. Indeed, these will depend on their social, economic, and cultural success, i.e., on how many citizens, workers, or tourists will recognise it as a "place". On the temporal distance that will elapse between the actions envisaged by the previous phases and the successful disposal of the oil plants, conditions can change. In this phase, we proceed with the reclamation of the new areas and activating residential, commercial, and managerial functions, in a regenerated urban system. The building will also follow the principles of regenerative design. It should be part of nature and the context providing open spaces for free aggregation.

\section{Results}

\subsection{Evaluation Framework of Landscape Services for Three Scenarios}

In an impenetrable context, such as the industrial area of East Naples, the design dealt with the feasibility of an intervention. For this purpose, the design strategy acts first on environmental and ecological issues and then addresses the question of a new residential settlement. In this way, the evaluation is no longer a tool to accompany the design, to define the preference of one scenario over another, but a critical activity to drive and support the actions.

Therefore, on three incremental scenarios, corresponding to three project steps seen previously, the intervention actions were defined:

1. Peri-urban forest (PF) materialises in the creation of forests, located on the edge of the building, with more or less dense coverage ( $10 \%$, sparse forest formations, and greater than $50 \%$, activated ecosystem recharge forest of scenarios 1 and 2);

2. Urban forest (UF) takes the form of the creation of woods, with coverage up to $50 \%$, for public use and is activated in scenario 1 with the creation of a natural park museum;

3. Wooded park (WP) takes the form of parks with green cover and trees or tree-lined rows, even with cover less than $10 \%$. These areas are minimal in the first two scenarios, but increase in the last, with the creation of parks within the new built area;

4. Other green spaces (GS) with trees, that take the form of green-roofed areas, including uncultivated green, wetlands, and green-covered production areas, such as the area of the eco-district or other industrial plants.

The evaluation uses the four categories of actions identified by indicators chosen through a comparison with planning experts. The goal is to evaluate the individual impacts and any increases in the actions themselves in the subsequent scenarios (Figure 7). 


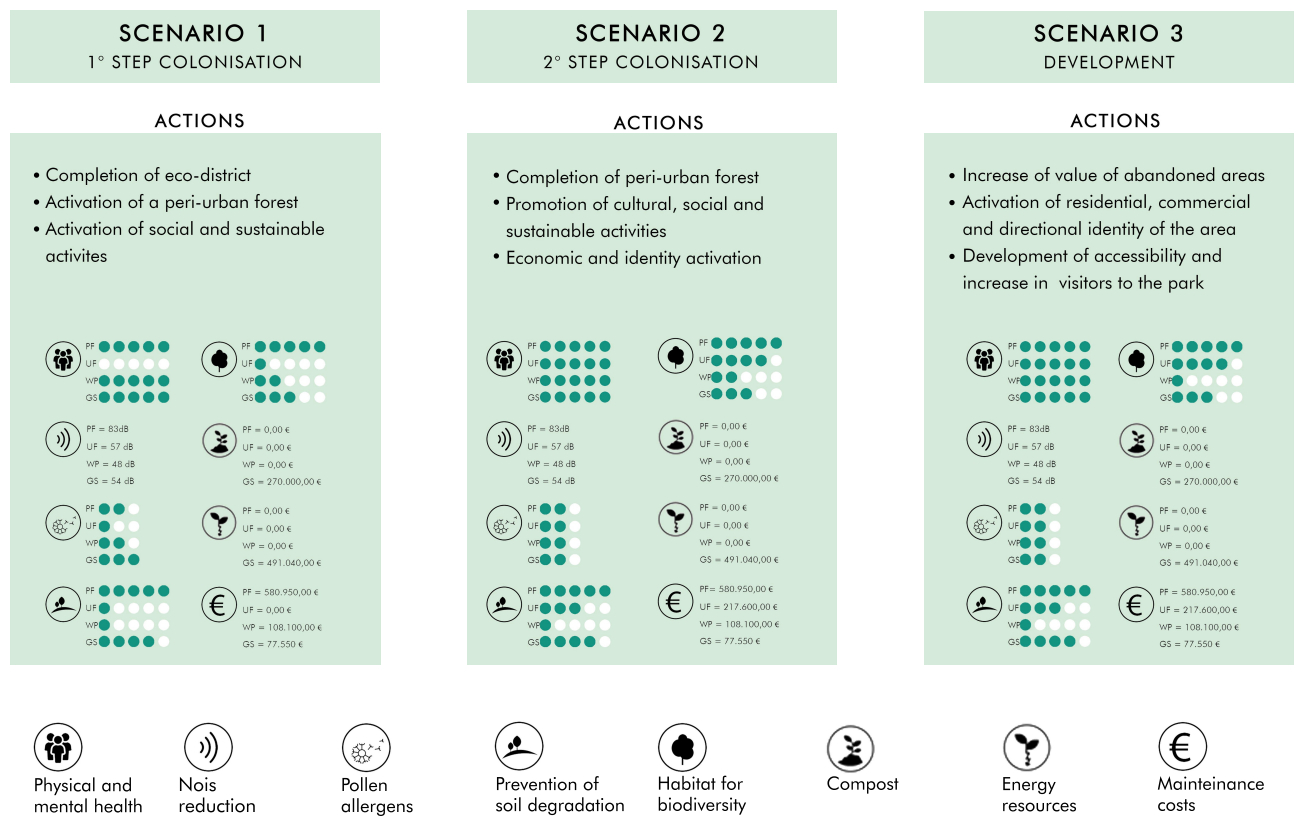

Figure 7. The classification of scenarios, actions, and indicators of the case study.

These indicators are an expression of different variables and use diverse rating scales, and each relates to specific criteria. For the case study of East Naples, the evaluation took into account some clusters of indicators, grouped according to the most similar criterion and able to include its description and characteristics.

Qualitative indicators selected are physical and mental health, pollen allergens, and prevention of soil degradation; quantitative indicators are related to noise reduction; and economic indicators, able to evaluate the revenues obtained from compost and energy resources and green maintenance costs. Some of these indicators can be explained by simple data, considering noise reduction, pollen allergens, compost production, energy resources, and maintenance costs. Others, on the other hand, are more complex and can be derived from the combination of simple indicators (see the aggregation in Figure 6). The latter, considered as composite indicators, do not have an arbitrary aggregation modality and role; therefore, it is the planners' team, involved in the project, to evaluate their construction. The indicator relating to the risk of allergens, for example, in some cases can be assessed together with the composite indicator relating to "Mental and physical health". In this case, however, its disintegration was preferred based on the importance that green implementation actions have on human well-being, especially to take into account the negative impacts that individual species can have on human health. One of these is the discomfort caused by pollen allergies, the degree of which depends on the level of allergenicity of the tree species, on the quantity of pollen produced per year, on the periods of the year when flowering takes place and in which monitoring is carried out, as well as the level of use of the area (i.e., the range of influence). For this reason, careful planning must take into account the correct choice of trees, bushes, and lawn to ensure that even allergy sufferers can stay without problems.

Once the simple indicator of pollen allergens has been analysed, it is, therefore, possible to consider the composite indicator that it influences, i.e., the mental and physical well-being of human beings. The balance between the natural and built environment is recognised as an influencing factor in urban health. Sedentary urban lifestyles, high levels of air pollution, and peculiarities of the urban microclimate can lead to substantial increases in diseases and discomforts, including mental stress, thermal discomfort and dehydration, as well as respiratory diseases associated with air pollution or insufficient physical activity, diabetes, cardiovascular disease, and obesity. So, the presence of green spaces can also have a positive effect on psychological well-being, reducing stress and improving mental health, promoting active lifestyles and regular physical activity, thus decreasing the risks 
deriving from obesity, diabetes type 2, coronary artery disease, respiratory diseases, and certain types of cancer. This composite indicator, due to the complexity of the different indicators it holds within it, is expressed with qualitative values (Figure 8a).

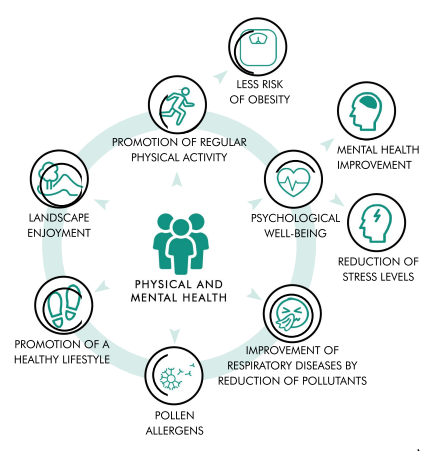

a)

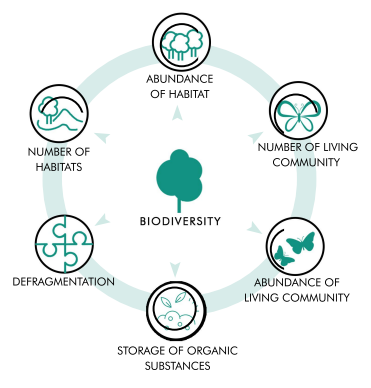

b)

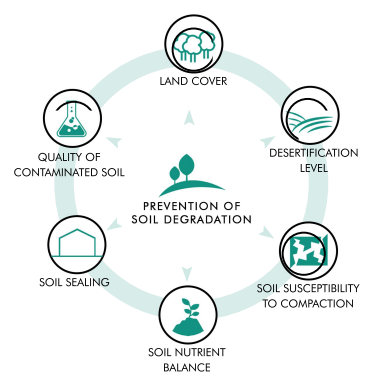

c)

Figure 8. The diagrams show the aggregation of simple data from which the composite indicators are made up: (a) Mental and physical health, (b) biodiversity, (c) prevention of soil degradation.

Another composite indicator is "Biodiversity" (Figure 8b). It is defined as the complexity of the structure of an environment, measured as a diversity of habitats, productivity, species richness, of the biomass contained in the different trophic levels, of the energy flows from which they are connected, by the speed of cycling of an element, by its capacity to perform a certain process (detoxification, soil consolidation, carbon dioxide organisation, etc.).

The specific case focused on an accurate analysis of the complexity of the structure of the environment, namely the Ecosystem and habitat richness, from which an abundance of living communities also derives. Based on the classification and data already provided by the Corine Land Cover maps [73] on the land cover, a legend was prepared that defined the area well, shared and compared with other databases. Therefore, a minimum unit of detail has been defined, i.e., the smallest entity to be mapped as a discrete entity, equal to 0.5 ha (the minimum unit considered by the FAO data), creating a regular square-meshed grid, the size of $71 \times 71 \mathrm{~m}$ with which the three scenarios are analysed (Figure 9).

Finally, the "Prevention of soil erosion" has been analysed (Figure 8c), which is defined as the ability to prevent the removal of the material that constitutes the soil from water and wind, through mechanical and chemical actions. Increased soil erosion, salinisation, desertification, and soil pollution are reducing fertility, water filtration capacity, and carbon storage capacity of urban and peri-urban soils, decreasing capacity food production and thereby threatening the livelihood and well-being of millions of people around the world. Trees can reduce soil erosion, and compaction and many cities have embraced the peri-urban forest solution as a way to prevent and improve soil degradation and erosion. These can offer opportunities for the restoration of degraded and/or abandoned soils and their reactivation, and they can support the processes of soil formation and increase their productivity and permeability; moreover, they can be a cost-effective tool to remedy contamination of the soil. Soil erosion prevention is a function of the degree of soil coverage, the degrees of waterproofing and desertification, the type of soil, and its susceptibility to compaction, as shown in the diagram of Figure $8 \mathrm{c}$.

To make operative the assessment of the impacts of a green area on human well-being and encourage the intelligent use of greenery within urban contexts, the Guidelines on urban and peri-urban forestry drawn up by Food and Agriculture Organization of the United Nations (FAO) proposes an assessment, in a range from 1 to 5 , from little to very relevant, for different categories (Figure 10). 

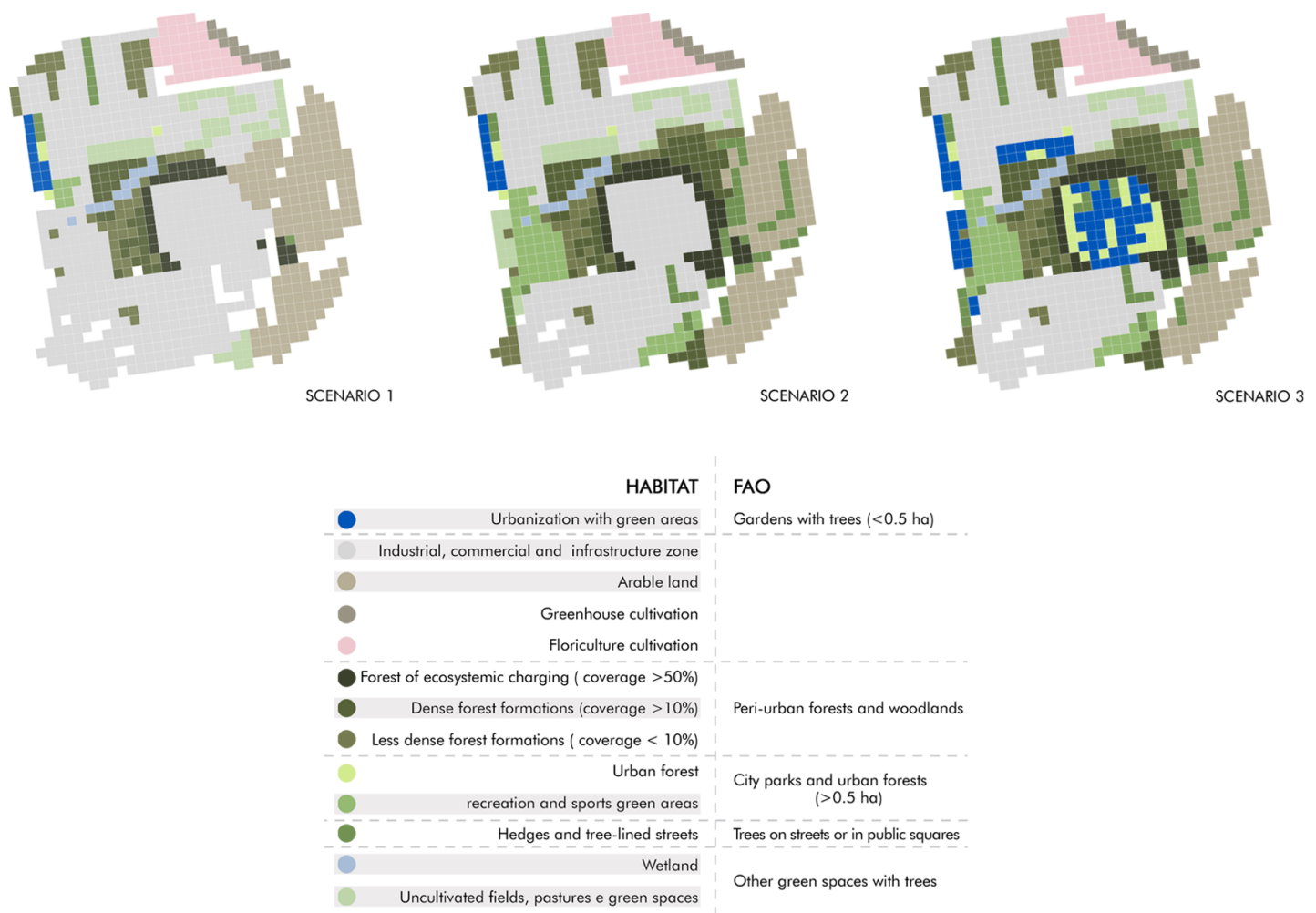

Figure 9. The square-meshed grid and its interpretation for the three scenarios.
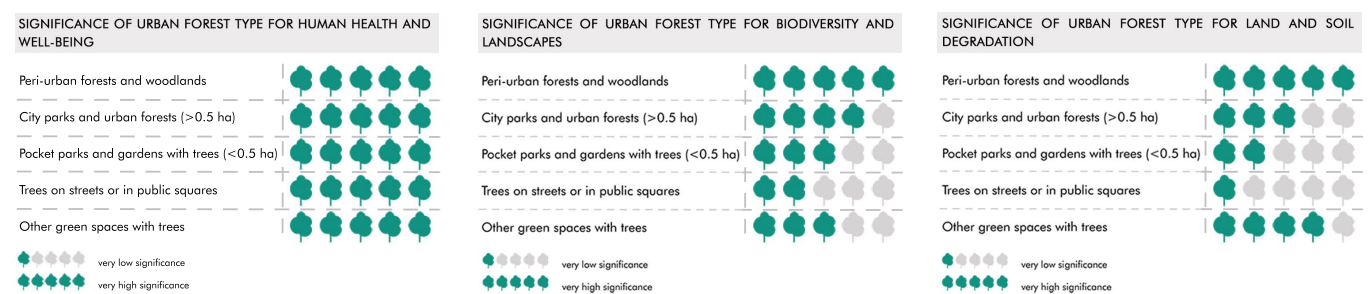

Figure 10. Elaboration from Guidelines on urban and peri-urban forestry of Food and Agriculture Organization (FAO).

\subsection{Elaboration and Results}

The purpose of this analysis is to compare the impacts that the same actions have on different scenarios. The aim is not to define the preferable scenario, but to highlight the impact of the individual actions so that, in collaboration with each other, they can be maximised the final goals.

In this sense, the multi-criteria PROMETHEE-GAIA method [61,62] is proposed as a negotiation tool for planning [74]. Indeed, it is part of the design process as a tool for controlling the impacts that a scenario produces by increasing each action from time to time (Figure 11). 


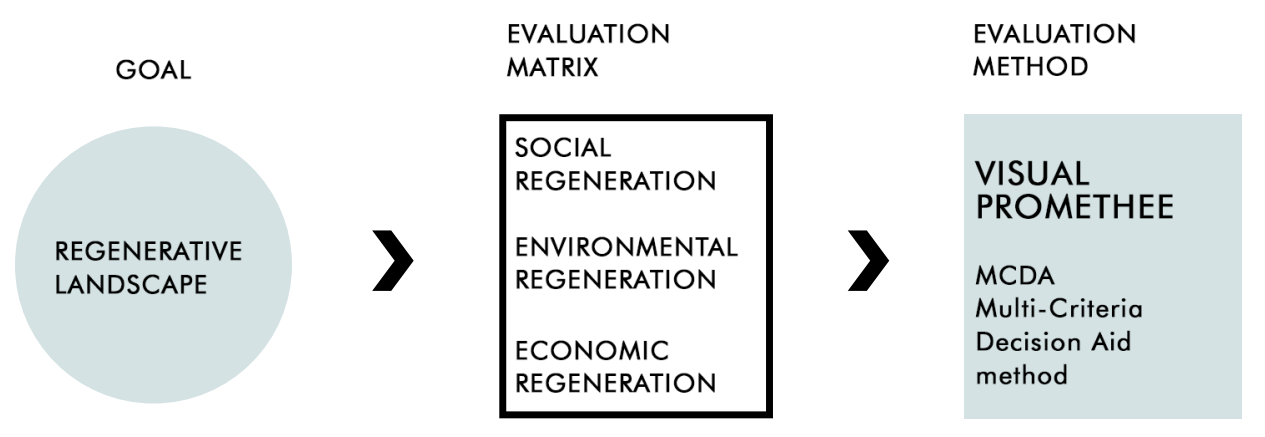

Figure 11. Development of methodological process.

The PROMETHEE-GAIA method, implemented by the Visual PROMETHEE software, is based on the calculation of the degrees of preference, assigning a score (between 0 and 1 ) to express how much one action is preferred to another from the decision-maker's point of view. Pairwise comparisons of alternatives are based on three preference flows to consolidate the results: Positive, negative, or net flow (which is obtained by subtracting negative flows from positive flows and must be maximised as they represent the balance between the global force and the global weakness of an action). The net score of an action is therefore always between -1 and 1 . To take into account all the criteria simultaneously, the decision-maker can provide the relative importance of each criterion, specifying the weights [75].

The evaluation took into consideration the three different incremental scenarios on which three matrices were built by positioning the project actions on the lines:

1. Peri-urban forest (PF);

2. Urban forest (UF) and squares;

3. Wooded park (WP) with tree-lined streets and squares

4. Other green spaces (GS) following the FAO indications.

The nine evaluation criteria, and the related indicators, divided into three clusters, were positioned on the columns of the evaluation matrix (Figure 12):

1. Social regeneration (icon in yellow), dependent on mental and physical health, noise reduction, and pollen allergens.

2. Environmental regeneration (icon in dark green), dependent on the prevention of soil erosion and habitat for the environment.

3. Economic regeneration (icon in grey), dependent on the production of compost and energy resources, maintenance costs, and new built surface.

\begin{tabular}{|c|c|c|c|c|c|c|c|c|c|c|c|c|}
\hline & 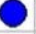 & Scenario1 & $\square$ & Physical\&me... & Noise reduct... & Pollen allerg... & Prevention... & Habitat for b... & Compost & Energy resou... & Maintenance... & New overbuil... \\
\hline & & Unit & & range & $d B$ & 3-point & range & impact & $\epsilon / \mathrm{kg}$ & $\epsilon / \mathrm{kg}$ & $€ / \mathrm{mq}$ & $\mathrm{mq}$ \\
\hline & & Cluster/Group & & 8 & 8 & 8 & $\gamma$ & $>$ & $\gamma$ & $>$ & $>$ & $>$ \\
\hline$\oplus$ & & Preferences & & & & & & & & & & \\
\hline (†) & & Statistics & & & & & & & & & & \\
\hline$\Theta$ & & Evaluations & & & & & & & & & & \\
\hline & 目 & Periurban forest & $\square$ & very high & 83 & average & very high & very high & $0.00 \epsilon$ & $€ 0.00$ & $\in 580,950.00$ & 0.00 \\
\hline & $\nabla$ & Urban forest & $\square$ & very low & 57 & low & very low & very low & $0.00 €$ & $€ 0.00$ & $\epsilon 0.00$ & 0.00 \\
\hline & $\nabla$ & Wooded park & $\square$ & very high & 48 & average & very low & low & $0.00 \epsilon$ & $€ 0.00$ & $€ 108,100.00$ & 0.00 \\
\hline & $\nabla$ & Other green spa... & $\square$ & very high & 54 & average & high & moderate & $270,000.00 €$ & $€ 491,040.00$ & $\in 77,550.00$ & 0.00 \\
\hline
\end{tabular}

Figure 12. The evaluation matrix.

Once the problem was structured hierarchically, the evaluation took into consideration the three different incremental scenarios on which three comparable matrices were built, using the one in 
Figure 12 as a model. This system shows how the preference for specific actions can improve or increase the position of the subsequent scenario.

\subsubsection{Scenario 1: The First Colonisation Phase}

The first phase of colonisation has the aim of starting to recover the identity of an area waiting for years, primarily through the environmental aspect. The evaluation aims to highlight the elements and actions with the most significant potential to lay the foundations for subsequent interventions.

The analysis let comparing the evaluation of alternatives:

1. The Walking Weights (Figure 13a) defines the preference of the realisation of other green spaces and the peri-urban forest, concerning the social (in yellow), environmental (in green), and economic (in grey) criteria;

2. The Gaia Plan (Figure 13b) shows, in a two-dimensional way, all aspects of the decision problem: The actions, criteria, and information on the preferences of the decision-maker. The actions (marked by arrows and points) closest to the decision stick (red axis) are those that maximise results. Furthermore, the proximity between arrows and points shows a certain level of proximity in the decision-making process (minor conflicts);

3. The GAIA Web (Figure 14) shows the attractive characteristics (i.e., the maximised indicators) of the two preferable actions.

The graphs show the positive result of the evaluation of the actions and the economic potential represented by the production of the eco-district. This, defined by the synergy between a project composting plant and the sludge produced by the treatment plant, produce both material and energy to be sold, and compost for the environmental activation of the soil and the creation of an ecosystem recharge forest. Indeed, these are the actions preferable to the others.

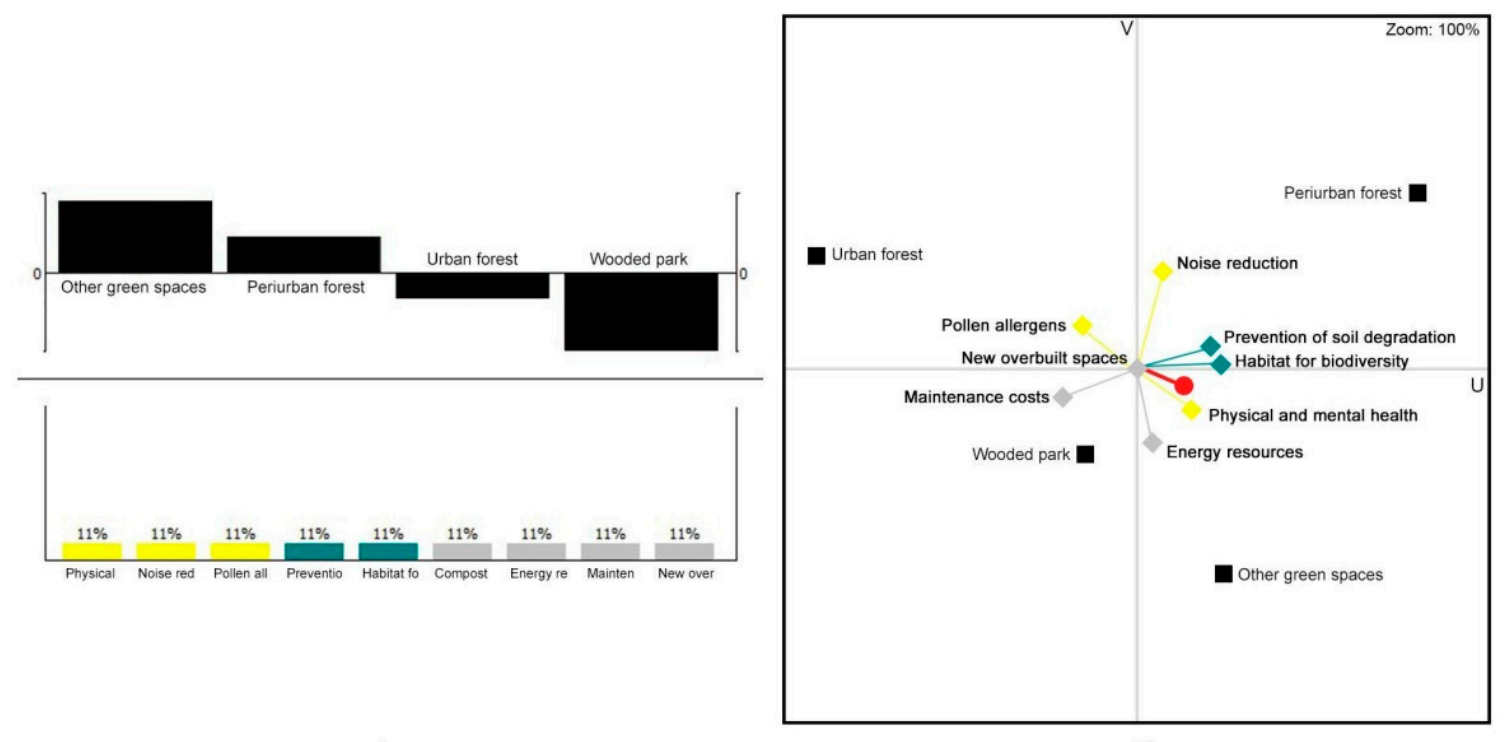

a)

b)

Figure 13. Evaluation of alternatives: (a) The Walking Weights; (b) the Gaia Plan. 


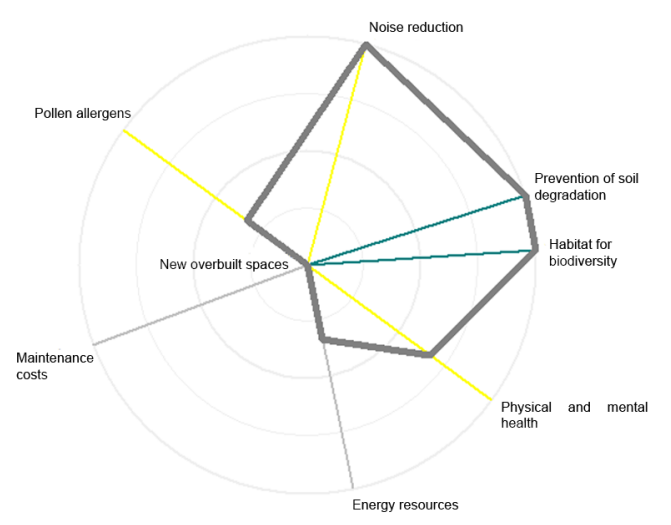

PERIURBAN SPACES

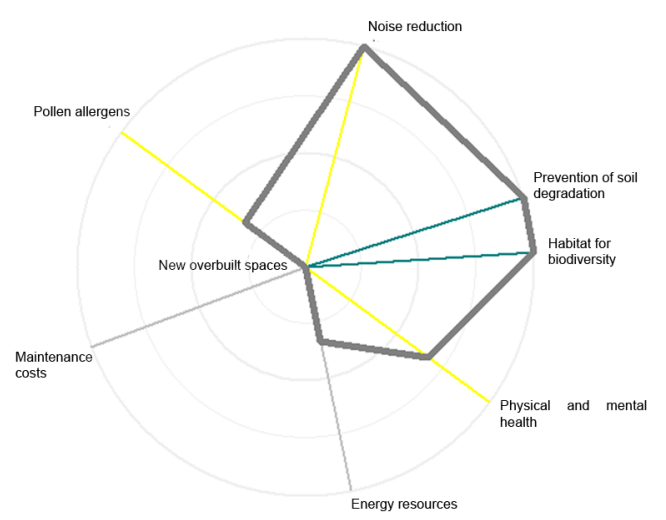

OTHER GREEN SPACES

Figure 14. Evaluation of alternatives: The GAIA Web.

\subsubsection{Scenario 2: The Second Colonisation Phase}

The second colonisation phase represents the second scenario: The one in which the peri-urban forest increases both in size and in the Ecosystem and social value. It also acquires economic value by becoming the Oil Park and Museum and temporary exhibitions and/or markets. The evaluation was carried out in a similar way to the previous scenario.

In this phase, the Gaia Plan (Figure 15a) shows the preference of the peri-urban forest, which has now enhanced its capabilities and GAIA Web (Figure 15b) defines the winning characteristics of the peri-urban forest.

Once again, the peri-urban forest shows its potential both from an environmental point of view-maximum is the potential of benefits for the prevention of soil and habitat erosion—but also as the most favourable place to host new functions and new buildings.

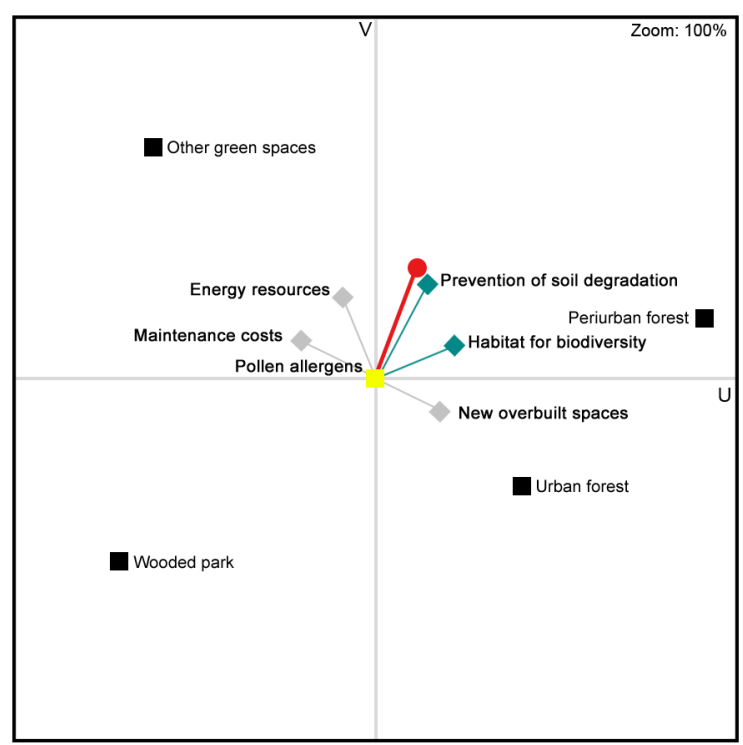

a)

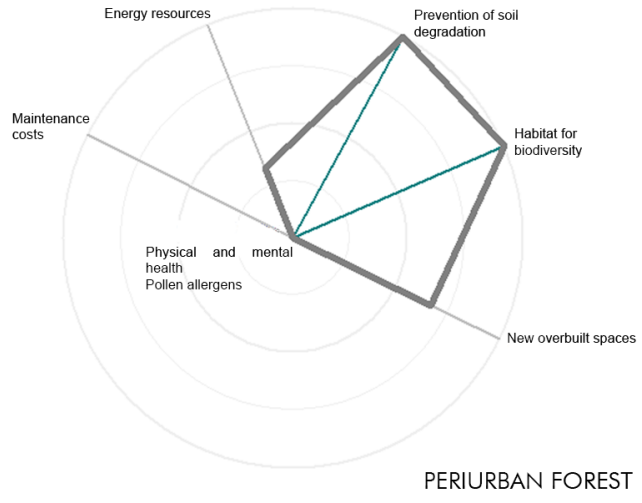

b)

Figure 15. Evaluation of alternatives: (a) Gaia Plan (b) GAIA Web.

\subsubsection{Scenario 3: The Final Scenario}

The last scenario defines the vision of post-disposal of oil plants and the construction of residential and commercial settlements, perfecting the environmental system generated in the previous phases in the three aspects of environmental, social, and economic regeneration. The actions evaluated are the 
same as in the earlier scenarios, taking into account the activities and interventions of the final project (Figure 16).

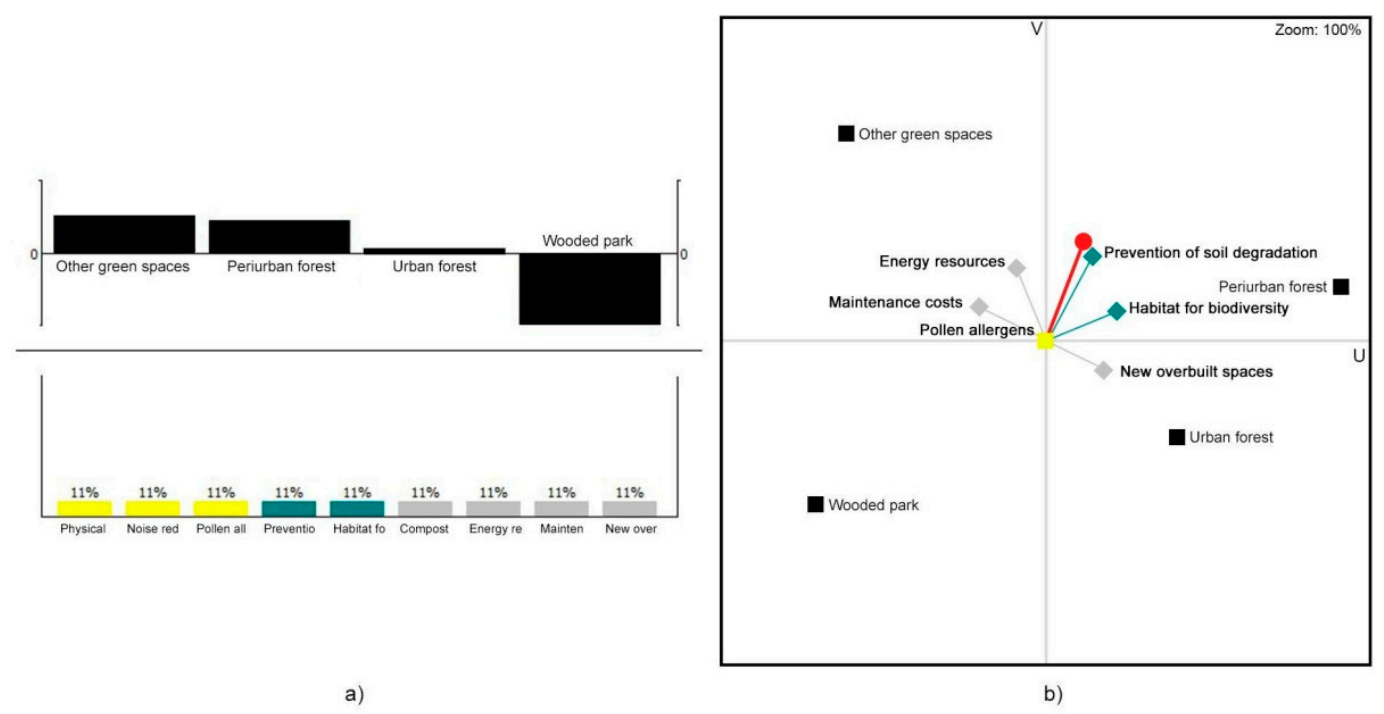

Figure 16. Evaluation of alternatives: (a) The Walking Weights; (b) the Gaia Plan.

The vision shows a now reclaimed environment, in which the panoramic view, human well-being, and economic activation have defined a drastic increase in real estate value. The evaluation once again shows the priority of the peri-urban forest even if the conditions have changed, still regarding the environmental aspects, rather than the economic ones.

\section{Discussion and Conclusions}

The regeneration strategies proposed for the East Naples wastescapes have been developed on the basis of a methodology elaborated considering the concept and the potentials of the Ecosystem and Landscape Services and Disservices integrated with the approach of Regenerative Design.

The methodology adopted explores the opportunity to drive a set of strategies for the urban regeneration of a wastescape identifying and implementing some criteria and indicators useful to describe the regeneration process considering social, environmental, and economic perspective, and to drive the transition from wastescapes to regenerativescapes, in a progressive and systemic logic to host adaptive processes developed in incremental phases.

The decision-making process structured for identifying and select a situated regeneration strategy for unresolved territories considers the relevance of multi-dimensional impacts of transformations and the opportunity to activate synergistic relationships among specific actions and scenarios, including an evolutive and dynamic process during the time.

The structuring of an incremental decision-making process, in which the evaluation assumes both the role of a decision support system and of a guide for the elaboration of the actions characterising the scenarios, allows activating an adaptive path, an integral part of the design process. At the same time, the evaluation becomes a negotiation tool to identify priorities and to build shared scenarios, not only a tool for assessing the impacts of scenarios. In this methodological context, the implementation of a multi-criteria evaluation allows to analyse and compare the three identified scenarios, to verify the impacts and to understand the opportunities of the possible regenerative actions and is considered as a decision support tool of the different design stages.

The initial question related to how it is possible to convert a wastescape into a regenerativescape underlines the need of approaches and tools suitable for identifying the complex values of the landscape, even if in critical conditions, and evaluating the interventions for the regeneration including different components and their mutual interplay. 
The elaboration of the decision-making process, in its main phases (Knowledge, Design, and Evaluation), faced some critical aspects. One of the most relevant is related to the difficulty to specify some environmental data explicitly and to assess the possible impacts. To get around this problem, it was necessary to refer to values already defined in general by the FAO [76].

The elaboration of a decision-making process in phases, in which the scenarios are configured according to an incremental approach, allows highlighting how the dimension of time is essential in the implementation of a regeneration path, which is structured in a flexible and adaptive way. It is possible to underline how a regenerative process can determine not only benefits from an environmental and social point of view, but also an economic point of view. Indeed, as seen previously, scenario 3 acts on the environmental and social aspects, and especially on the economic ones, defining a drastic increase in the real estate value, therefore the activation of a market with the related demand and offer (currently non-existent).

The analysis must be comparable to be valid. All the scenarios have the environmental aspect in common, selected also taking into consideration the panorama of research within which the case study has been inserted. It is, therefore, probable that the chosen indicators do not fully satisfy the efficiency of the last scenario. Compared to the latter, the evaluation, while not showing its full potential, aimed to demonstrate its priority.

The PROMETHEE-GAIA method [77] has been selected over other multi-criteria analysis methods since it allows to define the preference of an alternative to the others, obtaining a ranking among these with a clear comparison of indicators, offering the opportunity to assign different weights the criteria, for the definition of a Sensitivity analysis, and allowing a constructive debate between the planners' team and the decision-maker. The GAIA plane offers itself as a descriptive tool that supports the PROMETHEE method and provides a powerful graphical representation of the results, useful for understanding the conflicts between the criteria and for addressing the problem of the weights related to them. Furthermore, this method allows the decision-maker to overcome the problem of comparability of different data—qualitative and quantitative—without requiring any normalisation [78].

This research defined both a theoretical framework and a methodology to wastescape regeneration. Starting from the research carried out within the REPAiR project, an approach and an evaluation framework have been elaborated for the regeneration of waste landscapes, appreciated as active drivers of environmental and socio-economic services for the peri-urban landscape. The regenerative and systemic design approaches are the basis for the evaluation and transformation of a wastescape, that source of negative impacts, into a regenerative landscape, a place designed with nature to provide multi-dimensional services. We defined this kind of landscape a regenerativescape, able to combine the opportunities of Regenerative Design and the potentials of a healthy landscape. The concept of regenerativescape allows outlining a multi-dimensional approach for the regeneration of peri-urban territories, in which urban metabolism becomes determinant for the identification of possible actions of intervention, for the structuring of the decision-making process and the construction of a model of transition, also transferable in other contexts. A regenerativescape is a landscape that activates processes of self-regeneration and, at the same time, can trigger regenerative processes in neighbouring territories, promoting positive value chains. To implement a regenerativescape approach, the ES and LS have been analysed concerning the satisfaction of basic human needs, and also considering the EDS in the evaluation framework. The methodology applied to the case study of the industrial area of East Naples has addressed the scenarios of the wastescape regeneration by proposing dynamic and adaptive strategies, designed for progressive actions to implement in the selected context. The criteria and indicators have been defined following the theoretical approach to the regeneration of wastescape, and constitute a site-specific proposal concerning urban dimension analysis of the case study area. The results, obtained by the PROMETHEE-GAIA method, provided a basis of knowledge and discussion for decision-makers and the stakeholders involved in the transformation of the area, and are adaptable and evaluable by modifying the elements of the project scenarios according to more specific purposes. The defined methodology, therefore, proposes itself as an adaptive and incremental framework for the 
progressive implementation of a regenerativescape strategy. In the next developments of the research, to give a more articulated answer to the question how to convert a wastescape into a regenerativescape, it is relevant to consider regeneration processes focused on social and cultural components, attentive to both the material and immaterial dimensions of the transition, consistent with an inclusive Regenerative Design approach, and able to make operative a human-scale development.

Author Contributions: The authors jointly conceived and developed the approach and decided on the overall objective and structure of the paper. In particular, conceptualisation and methodology, M.C.; investigation and validation, writing original draft, writing, review and editing, C.M.; methodology, investigation, formal analysis, data curation and software, writing original draft, M.R.T. and M.S. All authors have read and agreed to the published version of the manuscript.

Funding: This research has received funding from the European Horizon 2020 funded research 'REPAiR: REsource Management in Peri-urban AReas: Going Beyond Urban Metabolism'. This article reflects only the author's view. The Commission is not responsible for any use that may be made of the information it contains.

Conflicts of Interest: The authors declare no conflict of interest.

\section{References}

1. European Union. United Nations Human Settlements Programme. In The State of European Cities 2016; European Commission, UN Habitat: Brussels, Belgium, 2016.

2. Atkinson, R. The Emerging' Urban Agenda' and the European Spatial Development Perspective: Towards an EU Urban Policy? Eur. Plan. Stud. 2001, 9, 385-406. [CrossRef]

3. Tisserant, A.; Pauliuk, S.; Merciai, S.; Schmidt, J.; Fry, J.; Wood, R.; Tukker, A. Solid Waste and the Circular Economy: A Global Analysis of Waste Treatment and Waste Footprints. J. Ind. Ecol. 2017, 21, 628-640. [CrossRef]

4. Keeney, R.L.; Raiffa, H. Decisions with Multiple Objectives: Preferences and Value Tradeoffs; Cambridge University Press: Cambridge, UK, 1993.

5. United Nations General Assembly. New Urban Agenda A/RES/71/256; United Nations: New York, NY, USA, 2017.

6. Amenta, L.; van Timmeren, A. Beyond wastescapes: Towards circular landscapes. Addressing the spatial dimension of circularity through the regeneration of wastescapes. Sustainability 2018, 10, 4740. [CrossRef]

7. Russo, M.; Amenta, L.; Attademo, A.; Cerreta, M.; Formato, E.; Remoy, H.; van der Leer, J.; Varjú, V.; Arciniegas, G. D 5.1: PULLs Handbook; EU Commission Participant Portal: Brussels, Belgium, 2017; Grant Agreement No 688920.

8. Alexander Wandl, D.I.; Nadin, V.; Zonneveld, W.; Rooij, R. Beyond urban-rural classifications: Characterising and mapping territories-in-between across Europe. Landsc. Urban Plan. 2014, 130, 50-63. [CrossRef]

9. Amenta, L.; Attademo, A.; Remøy, H.; Berruti, G.; Cerreta, M.; Formato, E.; Palestino, M.F.; Russo, M. Managing the transition towards circular metabolism: Living labs as a co-creation approach. Urban Plan. 2019, 4, 5-18. [CrossRef]

10. Cerreta, M.; Inglese, P.; Mazzarella, C. A hybrid decision-making process for wastescapes remediation. Geodesign, LCA, Urban Living Lab interplay. In Environmental and Territorial Modelling for Planning and Design; Antonio, L., Gargiulo, C., Eds.; FedOAPress: Naples, Italy, 2018; pp. 603-610.

11. Garzilli, F.; Mazzarella, C.; Vittiglio, V. Integrated Approaches for Peri- Urban Wastescapes: Eco-Innovative Strategies of the REPAiR Project in the Naples Case Study. Int. J. Urban Plan. Smart Cities 2020, 1, 43-58. [CrossRef]

12. Berger, A. Drosscape, Wasting Land in Urban AMERICA; Princeton: New York, NY, USA, 2006.

13. Czapiewski, K.; Pan, I.; Hcu, T.F.; Tud, E.H.; Rki, M.; Hcu, A.O.; Federica, M.; Unina, P.; Ellen, S.; Fraser, T. D3.3 Process. Model for the Two Pilot Cases: Amsterdam, the Netherlands \& Naples, Italy. Version 2; EU Commission Participant Portal: Brussels, Belgium, 2018; Grant Agreement No 688920.

14. Secchi, B. Il Futuro si Costruisce Giorno per Giorno. Riflessioni su Spazio, Società e Progetto. A Cura di Giulia Fini. Con Scritti di Paola Viganò e Patrizia Gabellini; Editore, Donzelli Editore: Rome, Italy, 2015; ISBN 978-88-6843-194-5.

15. Stessel, R.I. Recycling and Resource Recovery Engineering; Springer: Berlin/Heidelberg, Germany, 1996; ISBN 978-3-642-80221-8. 
16. Ellen MacArthur Foundation. Circularity in the Built Environment: Case Studies. 2016, pp. 1-72. Available online: https://www.ellenmacarthurfoundation.org/assets/downloads/Built-Env-Co.Project.pdf (accessed on 19 August 2020).

17. Williams, J. Circular cities: Challenges to implementing looping actions. Sustainability 2019, 11, 423. [CrossRef]

18. Attademo, A.; Formato, E. (Eds.) Fringe Shifts. Transforming Planning for New Suburban Habitats; Listlab Editor: Trento-Barcellona, Italy, 2019; ISBN 9788899854300.

19. Gómez-Baggethun, E.; Gren, Å.; Barton, D.N.; Langemeyer, J.; McPhearson, T.; O'farrell, P.; Andersson, E.; Hamstead, Z.; Kremer, P. Urban ecosystem services. In Urbanisation, Biodiversity and Ecosystem Services: Challenges and Opportunities: A Global Assessment; Springer: Dordrecht, the Netherlands, 2013; ISBN 9789400770881.

20. Elmqvist, T.; Setälä, H.; Handel, S.N.; van der Ploeg, S.; Aronson, J.; Blignaut, J.N.; Gómez-Baggethun, E.; Nowak, D.J.; Kronenberg, J.; de Groot, R. Benefits of restoring ecosystem services in urban areas. Curr. Opin. Environ. Sustain. 2015, 14, 101-108. [CrossRef]

21. Geneletti, D.; Cortinovis, C.; Zardo, L.; Adem Esmail, B. Planning for Ecosystem Services in Cities; Springer Nature Switzerland AG: Cham, Switzerland, 2020; ISBN 978-3-030-20024-4.

22. Opdam, P. Implementing human health as a landscape service in collaborative landscape approaches. Landsc. Urban Plan. 2020, 199. [CrossRef]

23. Millenium Ecosystem Assessment. Ecosystems and Human Well-Being; Island Press: Washington, DC, USA, 2005; ISBN 9781610914840.

24. Max-Neef, M. Development and human needs. Real-Life Econ. 1992, 197-214. [CrossRef]

25. Cruz, I.; Stahel, A.; Max-Neef, M. Towards a systemic development approach: Building on the Human-Scale Development paradigm. Ecol. Econ. 2009, 68, 2021-2030. [CrossRef]

26. Costanza, R.; Fisher, B.; Ali, S.; Beer, C.; Bond, L.; Boumans, R.; Danigelis, N.L.; Dickinson, J.; Elliott, C.; Farley, J.; et al. Quality of life: An approach integrating opportunities, human needs, and subjective well-being. Ecol. Econ. 2007, 61, 267-276. [CrossRef]

27. Costanza, R. Social goals and the valuation of ecosystem services. Ecosystems 2000, 3, 4-10. [CrossRef]

28. Lyytimäki, J. Bad nature: Newspaper representations of ecosystem disservices. Urban For. Urban Green. 2014, 13, 418-424. [CrossRef]

29. Von Döhren, P.; Haase, D. Ecosystem disservices research: A review of the state of the art with a focus on cities. Ecol. Indic. 2015, 52, 490-497. [CrossRef]

30. Lyytimäki, J.; Petersen, L.K.; Normander, B.; Bezák, P. Nature as a nuisance? Ecosystem services and disservices to urban lifestyle. Environ. Sci. 2008, 5, 161-172. [CrossRef]

31. Lyytimäki, J. Ecosystem disservices: Embrace the catchword. Ecosyst. Serv. 2015, 12, 136. [CrossRef]

32. Villa, F.; Bagstad, K.J.; Voigt, B.; Johnson, G.W.; Athanasiadis, I.N.; Balbi, S. The misconception of ecosystem disservices: How a catchy term may yield the wrong messages for science and society. Ecosyst. Serv. 2014, 10, 52-53. [CrossRef]

33. Schaubroeck, T. A need for equal consideration of ecosystem disservices and services when valuing nature; countering arguments against disservices. Ecosyst. Serv. 2017, 26, 95-97. [CrossRef]

34. Shackleton, C.M.; Ruwanza, S.; Sinasson Sanni, G.K.; Bennett, S.; De Lacy, P.; Modipa, R.; Mtati, N.; Sachikonye, M.; Thondhlana, G. Unpacking Pandora's Box: Understanding and Categorising Ecosystem Disservices for Environmental Management and Human Wellbeing. Ecosystems 2016, 19, 587-600. [CrossRef]

35. Lyytimäki, J.; Sipilä, M. Hopping on one leg-The challenge of ecosystem disservices for urban green management. Urban For. Urban Green. 2009, 8, 309-315. [CrossRef]

36. Wang, R.; Li, F.; Hu, D.; Larry Li, B. Understanding eco-complexity: Social-Economic-Natural Complex Ecosystem approach. Ecol. Complex. 2011, 8, 15-29. [CrossRef]

37. Costanza, R.; de Groot, R.; Braat, L.; Kubiszewski, I.; Fioramonti, L.; Sutton, P.; Farber, S.; Grasso, M. Twenty years of ecosystem services: How far have we come and how far do we still need to go? Ecosyst. Serv. 2017, 28, 1-16. [CrossRef]

38. Lyle, J. Regenerative Design for Sustainable Development; John Wiley \& Sons Inc.: New York, NY, USA, 1994.

39. Du Plessis, C.; Brandon, P. An ecological worldview as basis for a regenerative sustainability paradigm for the built environment. J. Clean. Prod. 2015, 109, 53-61. [CrossRef] 
40. de Groot, R.S.; Alkemade, R.; Braat, L.; Hein, L.; Willemen, L. Challenges in integrating the concept of ecosystem services and values in landscape planning, management and decision making. Ecol. Complex. 2010, 7, 260-272. [CrossRef]

41. Aly, D.; Hassan, D.K.; Mohamed, S.; Hamhaber, J. Review article Human Needs as an Approach to Designed Landscapes. J. Nat. Resour. Dev. 2018, 8, 15-26.

42. Mang, P.; Reed, B. Regenerative Development and Design. In Encyclopedia of Sustainability Science and Technology; Springer: New York, NY, USA, 2019; pp. 1-28.

43. Mang, P.; Reed, B. Designing from place: A regenerative framework and methodology. Build. Res. Inf. 2012, 40, 23-38. [CrossRef]

44. Gibbons, L.V.; Cloutier, S.A.; Coseo, P.J.; Barakat, A. Regenerative development as an integrative paradigm and methodology for landscape sustainability. Sustainability 2018, 10, 1910. [CrossRef]

45. Gibbons, L.V.; Pearthree, G.; Cloutier, S.A.; Ehlenz, M.M. The development, application, and refinement of a Regenerative Development Evaluation Tool and indicators. Ecol. Indic. 2020, 108, 105698. [CrossRef]

46. Gou, Z.; Xie, X. Evolving green building: Triple bottom line or regenerative design? J. Clean. Prod. 2017, 153, 600-607. [CrossRef]

47. Capra, F. La Rete Della vita. Perché L'altruismo e alla Base Dell'evoluzione; BUR Rizzol. Rizzoli: Milano, Italy, 1997; ISBN 978-88-58-69196-0.

48. Naess, A. A Defence of the Deep Ecology Movement. Environ. Ethics 1984, 6, 265-270. [CrossRef]

49. Mang, P.; Reed, B. Regenerative Development and Design. In Sustainable Built Environments; Loftness, V., Haase, D., Eds.; Springer: New York, NY, USA, 2013; pp. 478-501.

50. Korhonen, J.; Honkasalo, A.; Seppälä, J. Circular Economy: The Concept and its Limitations. Ecol. Econ. 2018, 143, 37-46. [CrossRef]

51. Kirchherr, J.; Reike, D.; Hekkert, M. Conceptualising the circular economy: An analysis of 114 definitions. Resour. Conserv. Recycl. 2017, 127, 221-232. [CrossRef]

52. Ellen MacArthur Foundation. Growth within: A Circular Economy Vision for a Competitive Europe; Ellen MacArthur Foundation: Cowes, UK, 2015; Volume 100.

53. Scheel, C. Beyond sustainability. Transforming industrial zero-valued residues into increasing economic returns. J. Clean. Prod. 2016, 131, 376-386. [CrossRef]

54. McDonough, W.; Braungart, M. Dalla Culla Alla Culla. Come Conciliare Tutela Dell'ambiente, Equità Sociale e Sviluppo; BLU Edizioni: Torino, Italy, 2003.

55. Weidner, T.; Yang, A. The potential of urban agriculture in combination with organic waste valorisation: Assessment of resource flows and emissions for two european cities. J. Clean. Prod. 2020, 244, 118490. [CrossRef]

56. de Souza, V.; Bloemhof-Ruwaard, J.; Borsato, M. Towards Regenerative Supply Networks: A design framework proposal. J. Clean. Prod. 2019, 221, 145-156. [CrossRef]

57. Broto, V.C.; Allen, A.; Rapoport, E. Interdisciplinary Perspectives on Urban Metabolism. J. Ind. Ecol. 2012, 16, 851-861. [CrossRef]

58. Chrysoulakis, N.; Lopes, M.; San José, R.; Grimmond, C.S.B.; Jones, M.B.; Magliulo, V.; Klostermann, J.E.M.; Synnefa, A.; Mitraka, Z.; Castro, E.A.; et al. Sustainable urban metabolism as a link between bio-physical sciences and urban planning: The BRIDGE project. Landsc. Urban Plan. 2013, 112, 100-117. [CrossRef]

59. Cui, X.; Wang, X.; Feng, Y. Examining urban metabolism: A material flow perspective on cities and their sustainability. J. Clean. Prod. 2019, 214,767-781. [CrossRef]

60. Poli, G. Hybrid Evaluation framework for Multifunctional Landscapes (HEMuL). In Theoretical Approaches and Operative Tools for Sustainability Science; Federico II University of Naples: Naples, Italy, 2017.

61. Mareschal, B.; Brans, J.P.; Vincke, P. PROMETHEE: A New Family of Outranking Methods in Multi-Criteria Analysis; ULB-Universite Libre de Bruxelles: Bruxelles, Belgium, 1984.

62. Brans, J.-P.; Mareschal, B. The PROMCALC \& GAIA decision support system for multi-criteria decision aid. Decis. Support. Syst. 1994, 12, 297-310. [CrossRef]

63. Behzadian, M.; Kazemzadeh, R.B.; Albadvi, A.; Aghdasi, M. PROMETHEE: A comprehensive literature review on methodologies and applications. Eur. J. Oper. Res. 2010, 200, 198-215. [CrossRef]

64. Brans, J.-P.; De Smet, Y. PROMETHEE Methods. In Multiple Criteria Decision Analysis: State of the Art Surveys; Greco, S., Ehrgott, M., Figueira, J.R., Eds.; Springer: New York, NY, USA, 2016; pp. 187-219, ISBN 978-1-4939-3094-4. 
65. Tsolaki-Fiaka, S.; Bathrellos, G.D.; Skilodimou, H.D. Multi-criteria decision analysis for an abandoned quarry in the Evros Region (NE Greece). Land 2018, 7, 43. [CrossRef]

66. Russo, M.; Lucci, R. Napoli Verso Oriente; CLEAN Edizioni: Naples, Italy, 2012.

67. De Groot, R. Function-analysis and valuation as a tool to assess land use conflicts in planning for sustainable, multi-functional landscapes. Landsc. Urban Plan. 2006, 75, 175-186. [CrossRef]

68. Batty, M.; Marshall, S. Thinking organic, acting civic: The paradox of planning for Cities in Evolution. Landsc. Urban Plan. 2017, 166, 4-14. [CrossRef]

69. Carta, M.; Lino, B. (Eds.) Urban Hyper-Metabolism; ARACNE Editrice: Ariccia, Italy, 2015; ISBN 9788854886544.

70. Brown, M.; Haselsteiner, E.; Apró, D.; Kopeva, D.; Luca, E.; Pulkkinen, K.-L.; Rizvanolli, B.V. RESTORE-Sustainability, Restorative to Regenerative: An Exploration in Progressing a Paradigm Shift in Built Environmental Thinking, from Sustainability to Restorative Sustainability and on to Regenerative Sustainability; Eurac Research: Bozen, Italy, 2018; ISBN 9783950460704.

71. Escobedo, F.J.; Kroeger, T.; Wagner, J.E. Urban forests and pollution mitigation: Analysing ecosystem services and disservices. Environ. Pollut. 2011, 159, 2078-2087. [CrossRef]

72. Fish, R.; Church, A.; Winter, M. Conceptualising cultural ecosystem services: A novel framework for research and critical engagement. Ecosyst. Serv. 2016, 21, 208-217. [CrossRef]

73. Büttner, G.; Feranec, J.; Jaffrain, G.; Mari, L.; Maucha, G.; Soukup, T. The CORINE land cover 2000 project. EARSeL eProceedings 2004, 3, 331-346.

74. Cerreta, M.; Daldanise, G.; Sposito, S. Culture-led regeneration for urban spaces. Monitoring complex values networks in action. Urbani Izziv 2018, 19, 9-28. [CrossRef]

75. Ishizaka, A.; Nemery, P. Multi-Criteria Decision Analysis: Methods and Software; John Wiley \& Sons, Ltd.: Chichester, UK, 2013; ISBN 1118644913.

76. Salbitano, F.; Borelli, S.; Conigliaro, M.; Chen, Y. Guidelines on Urban and Peri-Urban Forestry; FAO Forestry Paper N. 178; Salbitano, F., Borelli, S., Conigliano, M., Chen, Y., Eds.; FAO: Rome, Italy, 2016; ISBN 925109442X.

77. Brans, J.-P.; Mareschal, B. Prométhée-Gaia: Une Méthodologie D'aide à la Décision en Présence de Critères Multiples; Éditions de l’Université de Bruxelles: Bruxelles, Belgium, 2002; ISBN 2800412909.

78. Ishizaka, A.; Nemery, P. Selecting the best statistical distribution with PROMETHEE and GAIA. Comput. Ind. Eng. 2011, 61, 958-969. [CrossRef]

(C) 2020 by the authors. Licensee MDPI, Basel, Switzerland. This article is an open access article distributed under the terms and conditions of the Creative Commons Attribution (CC BY) license (http://creativecommons.org/licenses/by/4.0/). 